\title{
DOR E GoZo NA PSICANÁLISE: UMA REVISÃO 1
}

\author{
Patrícia do Socorro Nunes Pereira2 \\ Roseane Freitas Nicolaus \\ Jamile Luz Morais Monteiro4
}

\section{RESUMO}

A dor sentida no corpo sem causa orgânica justificada suporta um modo de satisfação pulsional, um gozo definido por Lacan no Seminário XX como fora-dalinguagem sendo inacessível às palavras, aparecendo para o sujeito na repetição e está relacionado ao prazer que comporta um sofrimento, ligado ao masoquismo primário (Lacan,1959-60/2009). O que coaduna ao que Freud (1920/2006) estabelece como um prazer na dor manifestado na compulsão a repetição ligada à pulsão de morte. Tais manifestações que acometem o sujeito, deixando-o muitas vezes paralisado em meio a suas dores, resistem ao tratamento e a seu diagnóstico. A partir das teorizações de Freud e Lacan discutiremos sobre a dor e os mecanismos envolvidos em seu processo.

PalaVRas-Chave: Dor Corporal; Pulsão; Gozo; Psicanálise.

1 Trabalho feito a partir de um recorte da dissertação de mestrado de Patrícia do Socorro Nunes Pereira, intitulada: Dor e Angústia: uma discussão psicanalítica, pesquisa realizada pelo Programa de PósGraduação em Psicologia da UFPA (PPGP)

2 Psicanalista, Psicóloga, Mestre em psicologia pelo PPGP/UFPA. Psicóloga Clínica (Clínica de psicologia/FADESP/UFPA) e Preceptora em Clínica Psicanalítica na UNAMA. Endereço: TV. Timbó, 1348 - BL A, apt.. 101 - Bairro: Pedreira. CEP: 66083-049. Belém - Pará. Telefone: (91) 98291-6087. E-mail: patnunespereira@yahoo.com.br

3 Professora Associada do Programa de Pós-graduação e da Faculdade de psicologia da Universidade Federal do Pará (UFPA). Psicanalista. Membro da Escola Letra Freudiana. Endereço: Av. Generalíssimo Deodoro, 1878 - Apto. 601 - Bairro: Nazaré. CEP: 66040-140. Belém - Pará. Telefone: (91) 99112-1108. E-mail: rf-nicolau@uol.com.br

4 Professora Adjunta do curso de Psicologia (UFT), psicanalista. Mestre em Psicologia (UFPA). Doutorada em Psicologia Social (PUC-SP). Especialização/Residência Multiprofissional em Saúde (HUJBB-UFPA). Endereço: Quadra 304 Norte Alameda $01 \mathrm{~s} / \mathrm{n}$ apt 603 bloco 3. BAIRRO: Plano Diretor Norte, Residencial Montenegro. CEP 77006-354 Palmas, Tocantins. E-mail: jamile@uft.edu.br 
Propomos uma reflexão sobre a dor física e sua relação com o gozo, a considerar que esta, uma vez sentida sem causa orgânica justificada, suporta um modo de satisfação pulsional, ou seja, um gozo definido por Lacan no Seminário XX como fora-da-linguagem sendo inacessível às palavras, aparecendo na repetição. $O$ conceito de gozo em Lacan (1959-60/2009), embora tenha passado por diversas reformulações no decorrer de sua obra, de modo geral, está relacionado ao prazer que comporta um sofrimento, implicado com o que está além do princípio do prazer ligado ao masoquismo primário. O que coaduna ao que Freud (1920/2006) estabelece como um prazer na dor manifestado na compulsão a repetição ligada à pulsão de morte. Observa-se que a dor como manifestação somática, ao não apresentar uma localização orgânica que a explique, resiste a diagnósticos e tratamentos, nem sempre respondendo ao modelo médico. Diante disso, faz-se necessário construir um saber em torno dessas manifestações que acometem o sujeito - deixando-o muitas vezes paralisado em meio a suas dores - assim como a relação que este estabelece com sua dor sob a forma de gozo.

Para adentrarmos à discussão sobre a dor e sua relação com o gozo recorremos primeiramente à noção de corpo para a psicanálise, conceitualização essencial para abordar o que propomos. Assim sendo, iniciamos com o texto "À guisa de uma introdução ao narcisismo" de 1914, onde Freud descreve o processo de constituição de corpo pulsional.

Freud (1914/2004) retomando as considerações feitas nos "Três ensaios" sobre o autoerotismo, onde é definido como uma fase primitiva de obtenção de prazer pelas zonas erógenas - portanto, uma fase caracterizada por um corpo fragmentado. $O$ autor afirma que a passagem do autoerotismo para o narcisismo resulta no processo de constituição do Eu. A constituição de um corpo imaginário pela criança se dá através de seu primeiro cuidador (normalmente a mãe). Assim, constituindo-se como um corpo totalizado, ordenando-se em torno da imagem corporal, deixa de ser uma matéria orgânica e transforma-se em um corpo pulsional.

Através do narcisismo, a criança passa a investir libido não somente no corpo biológico, nas zonas erógenas, mas no seu próprio Eu. Posteriormente, com 0 aparecimento da libido objetal, a criança deixa de ter somente seu Eu como objeto de investimento libidinal, direcionando uma parte de sua libido aos objetos externos. Entretanto, apesar de a libido se direcionar aos objetos de fora, uma parte da libido 
sempre ficará retida no Eu. Este será o motivo pelo qual o sujeito poderá regredir, através do seu sintoma, a um estágio mais primitivo - seja ao narcisismo, no caso de um sintoma psiconeurótico, seja ao auto-erotismo, no caso de um fenômeno psicossomático.

Ainda no referido texto, o autor aponta para a capacidade do órgão de apresentar sensibilidade dolorosa sem que alteração alguma tenha ocorrido na sua estrutura. Observa que isso pode ser visto no estado de excitação dos órgãos genitais sem que estes estejam enfermos. A atividade vinda de uma parte do corpo, e que envia estímulos excitantes para a vida psíquica, pode ser designada como erogeneidade, possibilitando que o corpo seja então tomado como objeto de satisfação. Freud (1914/2004) atribui ainda tal erogeneidade a uma faculdade geral de todos os órgãos:

Quanto a um órgão apresentar uma sensibilidade dolorosa sem que tenha
ocorrido alteração alguma, encontraremos o protótipo disto no estado de
excitação dos órgãos genitais, que apresentam tais características sem
estarem propriamente enfermos [...]. Poderíamos então designar como
erogeneidade a atividade que emana de uma parte do corpo e envia
estímulos sexualmente excitantes em direção à vida psíquica [...]. Agora,
basta que arrisquemos apenas mais um passo: podemos considerar que a
erogeneidade é uma faculdade geral de todos os órgãos e, portanto, nos
referir a um aumento ou redução de erogeneidade em determinada parte do
corpo (FREUD, 1914/2004, p.104-105).

Esta movimentação que a zona erógena provoca no aparelho psíquico, apontada pelo autor, nos leva a pensar no conceito de pulsão, que tem sua origem em fontes de estímulo no interior do organismo, sendo sua manifestação vista como uma força de impacto que pressiona constantemente, fazendo com que nem mesmo as ações de fuga consigam eliminá-la, pois ela é "irremovível" (FREUD, 1915/2004).

Sobre o conceito de pulsão, Freud (1915/2004, p. 148) a define como "um conceito-limite entre o psíquico e o somático". Para o autor, conforme já mencionado a fonte da pulsão está no interior do corpo, esses estímulos, uma vez excitados, recebem uma pressão de trabalho psíquico em direção ao alcance de sua meta: a satisfação. Embora a meta seja sempre a mesma, os caminhos para sua obtenção são diversos, necessitando, para isso, do objeto para alcançá-la. O objeto - elemento mais variável da pulsão -, por não ser definido, impõe ao corpo um modo de funcionamento diferente e possibilita-Ihe ser tomado como objeto de obtenção de prazer pelo sujeito.

Psicanálise \& Barroco em revista | v.17, n. 3 | dezembro de 2019 
Assim, o corpo, do modo como é concebido pela psicanálise, é importante tanto para a constituição do sujeito quanto para sua vida psíquica, pois ao mesmo tempo que se constitui pelo corpo, o sujeito pode satisfazer-se dele. É um corpo erógeno que sofre a incidência da pulsão, o que por sua vez, impõe a ele um modo distinto de funcionamento que, experimenta sensações físicas como a dor e representa afetos que escapam da dimensão psíquica. $O$ sujeito, em sua constituição, tem seu corpo banhado por representações psíquicas através de seu primeiro cuidador, e é este mesmo corpo que, ao sofrer a interdição do falo, pode ser simbolizado, interpretado e decifrado. Porém, algo nesta operação escapa, e, quando isso acontece, a excitação corporal endógena toma este corpo real para a sua satisfação - como bem nos disse Freud ao apontar para o sintoma conversivo na histeria e para os sintomas físicos das neuroses que chamou de atuais.

\section{A Dor Nos Escritos Metapsicológicos De Freud}

Desde "O projeto para uma psicologia científica", Freud (1950[1895] /1996), já vem tecendo considerações a respeito do fenômeno da dor, caracterizando-a a partir de um registro econômico e o resultado da ruptura de barreiras protetoras. Para ele, a dor seria consequência de um excesso de energia que, por ultrapassar essas barreiras, deixaria rastros permanentes atrás de si, exigindo, assim, a distribuição por parte do aparelho psíquico. Ainda neste artigo, o autor assinala a oposição da experiência de dor à experiência de satisfação. Na experiência de dor é a qualidade do afeto que possibilita a relação entre dor e desprazer. A vivência de dor aparece neste texto, em oposição à experiência de satisfação, revela a origem da massa sensória que inaugura o psiquismo humano, adquirindo as feições de dor-pulsão. Freud vai retomar essa concepção da dor-pulsão ou pseudo-pulsão no texto $O$ recalque e desenvolve mais essa teorização no texto $O$ Ego e o ID que abordaremos mais à frente.

No texto "Tratamento Psíquico (ou Anímico)" de 1905, Freud se refere a dor, não apenas como um fenômeno físico, mas também como resultado da influência do psiquismo. Observa que a intensidade da dor é a mesma, não importando se sua origem é psíquica ou física. Ele ressalta que o fato de direcionar ou não a atenção para o fenômeno doloroso, resulta na sua manutenção ou desaparecimento, como afirma neste trecho: "[...] Assim como as dores são produzidas ou intensificadas em 
se voltando a atenção para elas, também desaparecem pelo desvio da atenção" (FREUD, 1905b/1996, p. 276). Nesse sentido, o estado psíquico poderia não só ser responsável pela origem e manutenção de processos patológicos, como teria papel fundamental para o processo de cura. Desse modo, o estado psíquico da expectativa poderia mobilizar uma série de forças psíquicas eficazes para a instauração e a cura das doenças físicas. Nasio (2008), reforça essa teorização freudiana e assinala que na psicanálise não existe diferença entre dor psíquica e dor física.

Freud retoma à problemática da dor em sua obra no texto "À guisa de uma introdução ao narcisismo" (1914/2004). Neste trabalho, Freud coloca a dor como paradigmática do narcisismo, dada a dificuldade de investigar seu processo de forma direta. Objetivando avaliar a distribuição da libido, nos casos em que a dor aparece como central, ele considera que uma pessoa acometida de dor não se interessa pelas coisas ao seu redor. Com relação aos objetos amorosos, também há a retirada do interesse libidinal, pressupondo-se que, durante a vivência de dor, o sujeito deixa de amar. Quanto à economia libidinal nesse estado, Freud (1914/2004, p. 103) ainda observa: "o homem enfermo retira suas catexias libidinais de volta para seu próprio Eu e as põe para fora novamente quando se recupera". A partir desta observação de Freud, podemos estender essa concepção ao sujeito acometido de dor física, no qual observa-se certa apatia e indiferença em relação aos acontecimentos do mundo externo, ficando evidente que nada lhe desperta interesse, além das situações que envolvem seu sofrimento e sua dor. Esta concepção pode nos dar também uma compreensão sobre a dificuldade do sujeito em sair de sua condição de dor, resistindo a reinvestir a libido no mundo exterior.

Em “O recalque”, Freud (1915/2004) recorre à dor física na tentativa de indicar as situações pulsionais como determinantes para o recalque. Considerando que ela tivesse alguma semelhança com a pulsão, chega a descrever a dor física como um estímulo externo que se torna interno, apresentando-se, assim, como uma fonte de excitação constante, que provoca aumento de tensão e que se revela tão imperativa quanto a pulsão. Devido a essas características, chega a descrevê-la como uma pseudo-pulsão conforme já mencionamos. Naquele momento, parece que tais esclarecimentos não foram de muita importância para Freud, que, empenhado em compreender os mecanismos do recalque, não se aprofundou nessa direção, abandonando-a para dedicar-se à investigação de outros processos que trouxessem 
resultados mais esclarecedores para a sua pesquisa sobre o mecanismo do recalque.

Em "Pulsões e destinos da pulsão", Freud (1915/2004) apresenta uma formulação da dor vinculada ao prazer no masoquismo e no sadismo. Ele afirma que a psicanálise nos mostra que o infligir dor (física) e provocar sofrimento psíquico (humilhação) não desempenha nenhum papel nas metas originais da pulsão. Contudo, uma vez estabelecida a transformação em masoquismo, a dor presta-se muito bem a produzir a finalidade masoquista passiva. Sobre isso, Freud (1915/2004, p. 153) pontua que: "Temos boas razões para supor que as sensações de dor, bem como as outras sensações de desprazer, transbordam para a excitação sexual e produzem um estado prazeroso, em nome do qual o desprazer da dor também pode ser aceito".

Desta maneira, quando o sentir dor se torna uma finalidade masoquista, também a meta sádica de causar dor pode surgir retrospectivamente. No entanto, o autor enfatiza que, ao infligir dores nos outros, quem a inflige se identifica com o objeto que sofre e pode desfrutá-las de modo masoquista. Portanto, em ambos os casos, sadismo e masoquismo, não é a dor que é fruída, mas a excitação sexual concomitante que ela desperta. Por esta razão, sentir prazer com a dor seria inicialmente uma meta masoquista, mas o comprazer-se com a dor do outro se tornaria uma meta pulsional do sádico. (FREUD, 1915/2004).

\section{O Fator Econômico Da Dor E O Circuito Pulsional}

Freud (1920/2006) em "Além do Princípio do prazer" se refere a dor como um tipo de excitação externa que rompe a camada protetora contra estímulos de determinada área, ocasionando desprazer. As excitações provenientes dessa área fluem continuamente para o aparelho psíquico, tal como ocorre com as excitações vindas do interior do aparelho. $O$ aparelho psíquico, inundado pelo excesso de excitação, não consegue mediar tais afluxos de energia. Assim, o excedente de energia não simbolizado surge como um afeto intenso e sem mediação psíquica.

A dor, aparecendo para o sujeito como algo intenso, avassalador, sentida no real do corpo, revela também um psiquismo fragilizado que não é capaz de simbolizar tamanha quantidade de afeto. Nessa perspectiva, podemos dizer que a dor física, decorrente desse afeto intenso e sem mediação, reflete a própria dor psíquica de um 
sujeito desamparado psiquicamente. Delouya (1999) ressalta que a dor nem é um sinal, nem antecipa tal como a angústia, mas é uma resposta ao esforço de ligação de um excesso no aparelho psíquico.

Em "O ego e o id" de 1923, Freud retoma a questão da dor e seu caráter de pseudo-pulsão, assinalando que a dor se dá como algo, ou coisa, que brota de dentro do aparelho, atravessando-o na vertical, para se apresentar à consciência como percepção interna e externa. Assim, a dor, ao se equivaler à pulsão, faz também uma exigência de trabalho ao psíquico por conta da íntima ligação que tem com o corpo, excitação essa que se origina no corpo, diante da qual ação nenhuma é capaz de provocar a fuga. Nessa linha do pensamento freudiano, o sentir dor se torna uma representação interna do corpo, significa a constatação de um corpo constituído de órgãos e a constatação da própria existência. No artigo "Inibições, Sintomas e Angústia"5, Freud (1926/1996) reafirma a analogia da dor com a pulsão, observando que, assim como a pulsão, a dor tem sua origem entre o soma e o psíquico, não sendo completamente somática ou psíquica. A dor, física ou psíquica, emerge, portanto, como um limite impreciso entre o corpo e a psique. Desse modo, a dorpulsão, ao se originar entre o corpo e o psíquico, traz consigo o caráter de limite entre psico-soma. Ou seja, assim como a pulsão, a dor é uma excitação contínua que se origina no interior do corpo.

O estatuto pulsional da dor conferido por Freud (1926/1996) pode ser o responsável pela persistência da dor física, a essa forma de satisfação pulsional da ordem da repetição Lacan (1959-1960/2009) chamará de gozo, o qual será abordado após as teorizações freudianas.

\section{Compulsão A RepetiçÃo E MAsoquismo Em Freud}

O gozo implica em sofrimento e está relacionado ao excesso que envolve risco de vida. Está referido ao corpo e remete ao além do princípio do prazer. O gozo, na definição de Freud (1920/2006) é pulsão de morte, uma compulsão a repetição. Embora, Freud não tenha usado o termo gozo para sua concepção, foi a partir dela que Lacan inicia sua teorização sobre o gozo.

5 O termo da tradução na edição utilizada é ansiedade, porém optou-se em usar o termo angústia por ser mais condizente com o sentido do termo em português. 
Na compulsão à repetição, Freud (1920/2006) explica que os mecanismos repetitivos e compulsivos são uma forma de dominar o excesso de excitação provocado pelo trauma. A repetição aparece nesta situação não apenas como fenômeno clínico, mas também como motor de elaboração psíquica, ou seja, como uma forma de tentar conter e ligar o excesso que invade o aparelho e que o deixa subjugado à força da pulsão de morte e de seus elementos irrepresentáveis. Logo, a repetição é uma das formas psíquicas eleitas pelo sujeito para lidar com o irrepresentável.

A repetição de situações desprazerosas e traumáticas, de acordo com Freud (1920/2006), apontam para uma tentativa precária e fracassada do indivíduo de obter êxito na domesticação da violência psíquica a qual está submetido. Esses recursos usados como uma forma de simbolizar, através do ato e da dor física, uma dor da alma, uma dor muito mais primitiva e indizível. Tentativa a qual o sujeito recorre para colocar-se como ativo, mas que, paradoxalmente, nos remete ao quanto ele está sob o domínio inescapável de um excesso pulsional.

Os mecanismos de elaboração e representação parecem não dar conta de tamanha exigência pulsional, promovendo a falência do psíquico e a emergência de respostas imediatas, como a compulsão à repetição. Tal compulsão possui um caráter imperativo e inescapável, deixando o sujeito passivo, impelido a se colocar em situações desagradáveis. Ela diz respeito a algo que não pôde ser representado e que retorna de forma repetitiva e compulsiva na tentativa de ser elaborado. Essas respostas constituem mecanismos de defesa precários e extremos, envolvendo comportamentos autodestrutivos, numa possibilidade de se inscrever no corpo aquilo que não consegue se inscrever no psiquismo. Na tentativa de representar o irrepresentável, o sujeito busca sair da posição que ocupa diante do excesso pulsional que o invade. Um acontecimento violento ou um acúmulo de excitações não elaborados põem então em evidência o fracasso do aparelho psíquico em sua capacidade de descarregar a excitação. Assim, a compulsão à repetição está relacionada à pulsão de morte e se opõe ao princípio do prazer (FREUD, 1920/2006), colocando o sujeito em posição masoquista.

Vemos em Freud (1924/2007) que o masoquismo erógeno surge a partir de uma parcela da pulsão de morte que permaneceu no Eu, fixada libidinalmente entre a dor e o prazer. O masoquismo erógeno, por um lado, se tornaria componente da libido 
e, por outro, tomaria como objeto o próprio organismo. O que está em jogo no masoquismo erógeno não é a dor em si, mas a excitação sexual que ela provoca. Portanto, o masoquismo erógeno seria o resquício da antiga fase de formação, tão essencial à vida, em que houve um amálgama entre pulsão de morte e Eros.

De acordo com Freud (1924/2007), é na relação entre o Eu e o supereu que a necessidade de sofrimento se acentua através do masoquismo moral, impondo uma satisfação através do sofrimento e da dor. Nesse tipo de masoquismo, o sofrimento é proveniente de qualquer lugar ou de qualquer pessoa, pois o que importa é tão somente o sofrimento. $O$ sujeito o tem como um apaziguamento de uma culpa inconsciente, ou melhor, uma necessidade de punição, muito embora não admita ter esse sentimento de culpa. Porém, o que o mantém no sofrimento é a culpa, ocasionando, desta forma, uma satisfação do inconsciente.

O masoquista está sempre tentando agir de forma inadequada para sentir necessidade de punição. É o sofrimento que torna mais valiosa a tendência masoquista. A satisfação que o doente estabelece com o sofrimento o fazem resistir a sair dessa condição, o que ocasiona a repetição das ações que o levam ao sofrimento. Freud (1924/1996) ressalta a resistência do paciente em sair do estado de sofrimento, devido ao somatório de culpa e de satisfação. Em muitos casos, o masoquista apenas substitui um sofrimento pelo outro, pois o que importa para ele é a manutenção de certa quantidade de sofrimento.

\section{Gozo E Desejo Em LACAN}

Na perspectiva de Lacan (1959-1960/2009), a posição masoquista, enquanto estruturante, está articulada à subjetividade. Quando o sujeito é inserido na linguagem ele é barrado pela estrutura significante. O corpo, ao ser marcado pelo significante, perde alguma coisa - o que se perde está fora do circuito simbólico, mas está lá, exsiste, está no real. Logo, o masoquismo moral vai além de uma zona erógena, pois o que está nele implicado é o sujeito enquanto objeto de gozo do Outro.

O circuito da pulsão contém o gozo masoquista de fazer-se objeto do Outro em prol de um gozo que força a barreira do princípio do prazer. A pulsão se enlaça no simbólico pela via do significante, que entra no circuito pulsional. Só o masoquismo comporta uma satisfação através da dor e do sofrimento, visto que a dor tensiona o 
aparelho psíquico para provocar satisfação, e o gozo comporta uma dor experimentada pelo próprio sujeito. (LACAN, 1959-1960/2009).

Lacan (1959-1960/2009), em "O seminário, livro 7", denomina de campo do gozo o que Freud chamou de masoquismo, o que está para além do princípio do prazer. Ele observa, ainda, que o campo do gozo é aberto quando se interdita algo. Quanto mais se interdita, mais se goza, pois se goza na transgressão da lei, da lei que organiza a civilização e a lei humana, no sentido de proibição. O gozo instaurado como impossível constitui o sujeito do desejo. A lei, assim como interdita o gozo, aponta a transgressão como um lugar de gozo.

A interdição constitui o sujeito do desejo, tornando-o desejante do reconhecimento do Outro como um fiador ou como uma garantia da existência desse Eu de desejo. Ser um Eu de desejo é desejar o reconhecimento, proveniente do Outro, de seu próprio desejo. É desejar que o Outro não somente reconheça seu valor, mas que também o reconheça enquanto valor. O sujeito quer ser então este valor que o desejo do Outro procura. Esse Outro - lugar do tesouro do significante, origem de toda bateria significante - de onde emana uma fala que insiste em se repetir, lhe demande algo. Isto porque a castração, incidindo tanto sobre o Outro como no sujeito, faz aparecer uma falta. A esta falta vem corresponder um significante, comumente representado pelo falo, que tem a propriedade de ser destacável do corpo. Enquanto significante da falta do Outro, o falo dá corpo ao gozo (LACAN 1960/1998).

Para Lacan (1960/1998), o homem é um sujeito dividido pelo desejo e, não sendo substância e nem existência, se define como um efeito de linguagem, possuindo com o gozo apenas uma relação mediada pelo significante fálico. Deixado sem garantias, uma vez que não existe o Outro do Outro, o homem vai constituir seu desejo como desejo do Outro. O gozo é interdito, feito da própria textura da linguagem, ele "está proibido a quem fala como tal, ou ainda, [...] ele só pode ser dito nas entrelinhas para quem quer que seja sujeito à Lei, já que a Lei se funda justamente nessa proibição" (LACAN, 1960/1998, p. 836). Se, por um lado, há a proibição do gozo pela Lei, por outro, esta regulará um gozo possível, sujeito aos impasses do desejo e articulado ao significante do falo-gozo. Este gozo possível é o gozo fálico. Lacan (1960/1998) refere que "A castração significa que é preciso que o gozo seja recusado, para que possa ser atingido na escala invertida da Lei do desejo" (LACAN, 1960/1998, p. 841). 
De acordo com Lacan (1972-1973/2008), embora tenhamos o direito de usar o gozo, este se reduz apenas a uma instância negativa, àquilo que não serve para nada. O gozo não tem utilidade nenhuma e o direito a ele não é um dever, mas se goza porque o superego, na qualidade de imperativo do gozo, ordena: goza! O gozar só aumenta esse imperativo egóico promovendo a infinitude. A relação do homem com o gozo é articulada com a falta e somente o gozo fálico é possível, pela via do significante que marca a borda do buraco - o significante fálico. O gozo sexual está ligado a um desejo, a uma possibilidade de satisfação, é um gozo fálico, que é nãotodo, de um ser falante cujas necessidades estão sempre implicadas numa outra satisfação inconsciente, a satisfação da fala, que pode ser dita ou não.

Lacan (1972-1973/2008) fala ainda de um outro gozo, um gozo do corpo, do ser, um gozo do Outro. O gozo do Outro está para além de uma possível abordagem por parte do sujeito, pois este gozo está fora da linguagem. Se, no gozo fálico, há a busca de um gozo sexual, no gozo do Outro temos o gozo do corpo que, como tal, nada diz sobre o corpo. Trata-se de um corpo assexuado, pois o que o faz sexuado é a linguagem através da nomeação e significação das partes do corpo. O gozo do ser é um gozo fora-da-linguagem, que suporta o corpo como tal e não o corpo mortificado pela linguagem. $O$ gozo do Outro está localizado na interseção do real com o imaginário, é o gozo que está fora da linguagem, do simbólico, mas não fora do corpo. O corpo doloroso, do qual não há causa orgânica definida tem uma forma de satisfação pulsional através da dor. Desta forma, podemos entender a dor como um modo particular de gozo, um gozo do corpo, o gozo do Outro, do qual nada se tem a dizer sobre ele, pois está fora da linguagem, sendo inacessível às palavras.

Do lado do gozo do Outro está o gozo feminino, um gozo que, assim como o gozo do corpo, é inacessível, por não corresponder a nenhum desejo e, portanto, não pode ser de forma alguma apreendido ou significantizado. Por não ser toda castrada, como diz Lacan (1972-1973/2008), o sexo da mulher só diz algo por intermédio do gozo do corpo.

O sujeito acometido de dor sem referencial orgânico que a justifique, está fixado na pulsão de morte. O caráter persistente da dor faz com que o sujeito permaneça em um gozo mortífero. Neste caso, a dor pode ser o preço pago pelo sujeito que se torna presa do gozo do corpo, o gozo do Outro. 


\section{A Dor É O Preço Pago Pelo Sujeito}

De acordo com Freud (1920/2006), um ferimento físico poderia proteger o psiquismo contra o desenvolvimento de uma neurose traumática. A dor física, é uma das reações defensivas escolhidas pelo sujeito diante do domínio da excitação traumática, embora não seja um ferimento, não deixa de ser uma medida arcaica utilizada pelo psiquismo para se defender dos efeitos devastadores do traumático. Desse modo, a convocação do corpo se apresenta como defesa do psiquismo, fazendo da dor o representante de um excesso.

Seguindo essa teorização freudiana, Assoun (1997) observa que, a neurose causa danos ao órgão e é sob o mando desses danos que o sofrimento neurótico torna-se acessível à terapia. É fato que a neurose comporta uma ponta orgânica e é uma forma de existência psíquica, que exige ser reconhecida em seus próprios direitos. Essas neuroses, de acordo com o autor, criam sintomas a partir de todos os órgãos, fazendo com que, além do sofrimento psíquico, haja um momento físico obrigado à neurose, ou seja, (ASSOUN, 1997, p. 25): um "momento de verdade que é a incidência física do sintoma: no órgão doente é necessário poder reconhecer a voz da neurose, sua contribuição ao distúrbio somático".

Assim, a dor enquanto padecimento do corpo representa uma fuga da neurose, o sujeito encontra na dor física um mecanismo contra a dor psíquica. O sintoma para Freud (1926/1996) é uma formação de compromisso passível de ser interpretada. Para Assoun (1997), o sintoma somático não é uma formação de compromisso, pois quando o sofrimento do sujeito vai em direção ao corpo, ele passa a sofrer do corpo e, embora não seja uma doença no sentido orgânico, ele deixa de se haver com sua neurose. Assumir o compromisso com o sintoma significa submeter-se às leis do inconsciente e se haver com sua neurose. Dizer que o sintoma toma o corpo, quer dizer que o sujeito endereça para si mesmo a mensagem que vem do Outro.

Assoun (1997, p. 29) observa ainda que: "O sintoma somático não é talvez mais do que um pensamento do corpo, pensamento que sobrevém no corpo e que se chama 'fantasma'. Ou mais exatamente: 'pensamento' que o corpo sugere ao fantasma" e conclui que a análise pode promover condições para que o sujeito possa associar o sintoma orgânico à sua neurose.

Conforme visto, a relação entre o paciente somático e sua neurose é marcada por uma necessidade de punição, o que faz com que o doente se apegue a seu 
padecimento. O efeito punitivo traz alívio ao sofrimento neurótico do paciente, na medida em que ao sofrer do corpo o paciente deixa de se haver com seu sofrimento psíquico, estabelecendo, assim, uma relação de satisfação e um ganho masoquista com sua dor, ou seja, uma relação de gozo. A dor e o sofrimento têm íntima relação com o gozo, no sentido de que neste estão implicados dor e prazer. O gozo tem a ver com o corpo, está relacionado ao além do princípio do prazer e remete a pulsão de morte. De acordo com a formulação de Lacan (1972-73/2008) é estabelecido como fora da linguagem, não está ligado a nenhum desejo, mas a uma possibilidade de satisfação pulsional. O corpo acometido de dor é uma forma de satisfação pulsional, um modo particular de gozo, um gozo do corpo, o gozo do Outro, fora da linguagem, sendo assim, inacessível às palavras.

\section{CONSIDERAÇões Finais}

Recorremos as teorizações de Freud e Lacan para abordamos acerca da dor e os elementos implicados em seu mecanismo, como o corpo, a pulsão, o trauma e o gozo. A concepção de corpo que ultrapassa a estrutura anatômica, no qual incide a pulsão, tornando-o um corpo erógeno e com isso uma forma distinta de funcionamento permitindo que o sujeito possa toma-lo como objeto de obtenção de prazer. É um corpo afetado pelo pensamento e pela linguagem, essa formulação nos permitiu compreender como a dor pode incidir nesse corpo pulsional e servir de arranjo para 0 sujeito. O percurso empreendido nos mostrou que o sujeito que apresenta dor física sem referencial orgânico que a justifique está envolto em toda uma trama que constitui sua subjetividade. Esta forma de dor suporta um modo de satisfação pulsional, deixando, muitas vezes, o sujeito paralisado em meio a suas dores e, ao mesmo tempo este resiste em sair de sua condição de sofrimento, dado o somatório de dor e prazer em forma de um gozo masoquista. A dor física pode ser uma saída diante do insuportável da dor psíquica e o preço pago pelo sujeito.

Embora, o caráter pulsional da dor em termos da repetição e da ordem do gozo seja uma dificuldade a mais ao tratamento, o sofrimento orgânico ao ser tomado como sintoma e o sujeito colocado a falar de sua dor - mesmo que resista em relacionar seu sofrimento físico com sua história de vida - na análise é possível promover condições para que o sujeito associe sua dor aos seus traumas e conflitos e, com isso facilitar 
Patrícia do Socorro Nunes Pereira, Roseane Freitas Nicolau e Jamile Luz Morais Monteiro

suas elaborações. Falar de seu sofrimento em vez de representar no corpo, pode possibilitar uma redução de gozo. 


\section{REFERÊNCIAS:}

ASSOUN, Paul-Laurent. Corps et Symptôme - Tome 1: Clinique du corps. Paris: Econômica Ed, 1997.

DELOUYA, D. A. A dor entre o corpo, seu anseio e a concepção de seu objeto. In: BERLINCK, T. M. (Org.). Dor. São Paulo: Escuta, 1999. p. 23-35.

FREUD, Sigmund (1905a). Três ensaios sobre a teoria da sexualidade. In: Edição Standard Brasileira das Obras Psicológicas Completas de Sigmund Freud. Rio de Janeiro: Imago 1996. V. VII. (1905b). Tratamento psíquico (ou anímico). In: Edição Standard Brasileira das Obras Psicológicas Completas de Sigmund Freud. Rio de Janeiro: Imago, 1996. V. II.

(1914). À guisa de uma introdução ao narcisismo. In: Obras Psicológicas de Sigmund Freud Escritos sobre a Psicologia do Inconsciente. Tradução de Luiz Alberto Hanns. Rio de Janeiro: Imago, 2004. V.1.

(1915). Pulsões e destinos da pulsão. In: Obras Psicológicas de Sigmund Freud Escritos sobre a Psicologia do Inconsciente. Tradução Luiz Alberto Hanns. Rio de Janeiro: Imago 2004. V. I.

. (1920). Além do princípio do prazer. In Obras Psicológicas de Sigmund Freud Escritos sobre a Psicologia do Inconsciente. Luiz Alberto Hanns (trad.). Rio de Janeiro: Imago, 2006. V. 2.

. (1923). O ego e o id. In: Edição Standard brasileira das obras psicológicas completas de Sigmund Freud: Rio de Janeiro: Imago, 1996. V. XIX.

. (1924). O problema econômico do masoquismo In: Obras psicológicas de Sigmund

Freud Escritos sobre a psicologia do inconsciente. Tradução de Luiz Alberto Hanns. Rio de Janeiro: Imago, 2007. V. 3.

. (1926) Inibições, Sintomas e Angústia. In: Edição Standard Brasileira das Obras Completas. Rio de Janeiro: Imago, 1996. V. XX.

(1950[1895]). Projeto para uma psicologia científica. In: Edição Standard

Brasileira das Obras Psicológicas Completas de Sigmund Freud. Rio de Janeiro: Imago, 1996. V. I.

LACAN, Jacques. (1959-1960). O Seminário. Livro 7: A ética na psicanálise. Rio de Janeiro: Jorge Zahar Editor, 2009.

(1960). Subversão do Sujeito e Dialética do Desejo no inconsciente freudiano. In:

Escritos. Rio de Janeiro: Jorge Zahar: 1998.

Psicanálise \& Barroco em revista | v.17, n. 3 | dezembro de 2019 
Patrícia do Socorro Nunes Pereira, Roseane Freitas Nicolau e Jamile Luz Morais

Monteiro

. (1972-1973). O Seminário. Livro 20: Mais, Ainda. 3ª Ed. Rio de Janeiro: Jorge

Zahar Editor, 2008.

NASIO, Juan David. A dor física: uma teoria psicanalítica da dor corporal. Tradução de André

Teles e Lucy Magalhães. Rio de Janeiro: Jorge Zahar Editor, 2008. 


\title{
Pain And Enjoyment In Psychoanalysis: A Review
}

\begin{abstract}
The pain felt in the body without justified organic cause supports a mode of drive satisfaction, an enjoyment defined by Lacan in Seminar XX as out-of-language being inaccessible to words, appearing to the subject in repetition and related to the pleasure that entails suffering, linked to primary masochism (Lacan, 1959-60/2009). This is in keeping with what Freud (1920/2006) establishes as a pleasure in pain manifested in the compulsion to repetition linked to the death drive. Such manifestations that affect the subject, leaving him often paralyzed in the midst of his pain, resist the treatment and its diagnosis. From the theorizations of Freud and Lacan we will discuss the pain and the mechanisms involved in its process.
\end{abstract}

KEYWORDS: Physical Pain; Drive; Enjoyment; Psychoanalysis 


\section{LA DOULEUR ET LA JOUISSANCE EN Psychanalyse: Une ReVISION}

\section{RÉSUMÉ}

La douleur ressentie dans le corps sans cause organique justifiée soutient un mode de pulsion la satisfaction, une jouissance définie par Lacan dans le Séminaire XX comme hors langue inaccessible aux mots, apparaissant pour le sujet en répétition est liée au plaisir de souffrir, lié au masochisme (Lacan, 1959-1960 / 2009). Cela correspond à ce que Freud (1920/2006) établit comme un plaisir dans la douleur se manifeste dans la compulsion de répétition liée à la pulsion de mort. De telles manifestations qui affectent le sujet, le laissant souvent paralysé au milieu de sa douleur, résistent au traitement et à son diagnostic. À partir des théorisations de Freud et Lacan, nous discuterons de la douleur et des mécanismes impliqués dans son processus.

MOTS-CLÉS: Douleur Corporelle; Pulsion; Jouissance; Psychanalyse 
Dor E Gozo Na Psicanálise: Uma Revisão

RECEBIDO EM 21-05-2019

APROVADO EM 25-10-2019

(C) 2019 Psicanálise \& Barroco em revista

http://www.seer.unirio.br/index.php/psicanalise-barroco/index

revista@psicanaliseebarroco.pro.br

Programa de Pós-Graduação em Memória Social — UNIRIO

Memória, Subjetividade e Criação

www.memoriasocial.pro.br/proposta-area.php 